\title{
A alfabetização e a heterogeneidade de conheci- mentos sobre a escrita no Brasil e na França
}

\author{
Nayanne Nayara Torres da Silva \\ Universidade de Pernambuco (Brasil) \\ Eliana Borges Correia de Albuquerque \\ Universidade Federal de Pernambuco (Brasil)
}

\section{Resumo}

Este artigo analisa as práticas de professoras do $1^{\circ}$ ano do ensino fundamental no Brasil e na França no atendimento à heterogeneidade de conhecimentos sobre a escrita alfabética dos alunos, assim como os diferentes níveis de apropriação do sistema de escrita das crianças de ambas as turmas ao início e final do ano letivo. $\bigcirc$ aporte teórico está pautado nos estudos de Ferreiro e Teberosky (1999); Ferreiro (200 1); Morais (2012); Goigoux (2007); entre outros. A partir da imersão nos dados, foi observado que as docentes mobilizam esquemas profissionais, posturas, gestos didáticos e gestos profissionais para atender à heterogeneidade de conhecimentos sobre a escrita alfabética dos alunos. Contudo, as diferentes maneiras como os mobilizam, atreladas aos conhecimentos que possuem sobre o que os alunos já sabem e o que ainda precisam aprender, resultov em diferenças significativas nas aprendizagens da escrita alfabética dos alunos brasileiros e franceses ao final do ano letivo.

Palavras-chave: Alfabetização. Heterogeneidade. Ensino. Aprendizagem.

\section{Literacy and the knowledge's heterogeneity about writing in Brazil and France}

\section{Abstract}

This paper analyzes the practices of first grade elementary school teachers in Brazil and France in dealing with the heterogeneity of students' knowledge about alphabetical writing, as well as the different levels of appropriation of the writing system of children in both classes at the beginning and end of the school year. The theoretical framework is based on the studies of Ferreiro and Teberosky (1999); Ferreiro (200 1); Morais (2012); Goigoux (2007); among others. From the immersion in the data, it was observed that the teachers mobilize professional schemes, postures, didactic gestures, and professional gestures to meet the heterogeneity of knowledge about students' alphabetic writing. However, the different ways in which they mobilize them, coupled with their knowledge about what students already know and what they still need to learn, resulted in significant differences in the alphabetic writing learning of Brazilian and French students at the end of the school year. Keywords: Literacy. Heterogeneity. Teaching. Learning. 


\section{La alfabetización y la heterogeneidad del conocimiento sobre la escritura en Brasil y en Francia}

\section{Resumen}

Este artículo analiza las prácticas de profesoras del primer año de educación primaria en Brasil y Francia para atender a la heterogeneidad de conocimientos sobre la escritura alfabética de los estudiantes, así como los diferentes niveles de apropiación del sistema de escritura de los niños de ambas clases al comienzo y al final del año escolar. El marco teórico se basa en los estudios de Ferreiro y Teberosky (1 999); Ferreiro (200 1); Morais (2012); Goigoux (2007); entre otros. A partir de la inmersión en los datos, se observó que los profesores movilizan esquemas profesionales, posturas, gestos didácticos y gestos profesionales para responder a la heterogeneidad de los conocimientos sobre la escritura alfabética de los alumnos. Sin embargo, las diferentes formas de movilizarlos, unidas a su conocimiento sobre lo que los alumnos ya saben y lo que aún necesitan aprender, dieron lugar a diferencias significativas en el aprendizaje de la escritura alfabética de los estudiantes brasileños y franceses al final del año escolar.

Palabras clave: Alfabetización. Heterogeneidad. Enseñanza. Aprendizaje.

\section{Introdução}

As ałuais discussões em torno do processo de alfabetização no Brasil, a exemplo da Política Nacional de Alfabetização (doravante PNA), produzida em 2019 pelo Ministério da Educação, sinalizam, dentre outros aspectos, para o uso da instrução fônica como um pilar para a aprendizagem da leitura e da escrita, o que nos faz remeter ao método fônico de alfabetização. Levantando a bandeira das evidências científicas, a atual política de alfabetização do governo Jair Bolsonaro se baseia em evidências de pesquisas experimentais desenvolvidas por países do primeiro mundo.

Dentre os países mencionados, o caderno da PNA traz a França como referência destacando as recomendações de instrução fônica contidas no "Observatório Nacional da Leitura", criado em 1997, para as práticas de alfabetização, sinalizando que o referido país faz uso do método fônico. Contudo, o documento brasileiro parece esquecer o conjunto de pesquisas empíricas que tem sido produzido no cenário nacional, desconsiderando a vasta contribuição que pesquisadores de norte a sul do Brasil têm dado às discussões da alfabetização por meio dos resultados de suas investigações.

O presente estudo se insere justamente nesse conjunto de pesquisas empíricas que além de analisar as práticas de alfabetização no contexto 
brasileiro, também analisou o contexto francês, o que nos possibilita questionar a maneira como a instrução fônica é defendida pela Política Nacional de Alfabetização. Conforme pudemos observar em nossa investigação, não existe, na França, a defesa pelo método fônico de alfabetização, mas, sim, uma variedade de ações mobilizadas pelas professoras alfabetizadoras no processo de ensino da leitura e da escrita.

Considerando que os saberes e as práticas das professoras alfabetizadoras são (re)inventadas cotidianamente na sala de aula na tentativa de desenvolver uma pedagogia diferenciada, que, conforme observa Chartier (2007), impõe-se com mais evidência na classe de alfabetização, apresentaremos neste artigo dados de uma pesquisa que visou investigar as práticas de professoras do $1^{\circ}$ ano do ensino fundamental no atendimento à heterogeneidade de conhecimentos dos alunos sobre a escrita alfabética no contexto do Brasil e da França como também a progressão dessa aprendizagem por parte das crianças dessas classes. Com isso, nosso objeto de investigação se contrapõe à homogeneidade que a PNA institui ao retomar um método de alfabetização de marcha sintética.

Nesse artigo, apresentaremos, inicialmente, algumas reflexões sobre as orientações oficiais para o ensino da leitura e da escrita no Brasil e na França, e sobre os saberes e as ações docentes mobilizados no cotidiano da sala de aula. Em seguida, após situarmos os aspectos metodológicos da pesquisa, discutiremos os resultados encontrados, assim como teceremos algumas considerações finais.

\section{As propostas curriculares para o ensino da leitura e da escrita no Brasil e na França}

Ao tratarmos das propostas curriculares que sinalizam o ensino da leitura e da escrita nas classes de alfabetização brasileiras e francesas, torna-se impreterível abordarmos a escolarização em ciclos, tendo em vista que a sua políitica, que elimina a retenção no ciclo de alfabetização, prima por um ensino que contemple as diferentes necessidades dos aprendizes. Na França, a turma de alfabetização se inscreve de forma institucional em um ciclo de três anos de aprendizagens fundamentais, mas o trabalho de apropriação da escrita alfabética se inicia ainda na educação infantil. Como bem pontuou 
Chartier (2007, p. 149): "[...] a aprendizagem da leitura e da escrita é, então, concebida como um processo longo, que começa no último ano da educação infantil e continua no ensino fundamental".

Programa de ensino francês relativo ao ciclo das aprendizagens fundamentais (ciclo 2), publicado no Boletim Oficial Especial n $n^{\circ} 11$ de 26 de novembro de 2015, explicita que, no referido ciclo, a língua francesa constitui o objeto de aprendizagem central e deve envolver a oralidade, a leitura e a escrita. Nessa proposta, a alfabetização não é vista como o ensino do código escrito realizado em um ano específico, mas como um processo que se inicia ainda na educação infantil.

Essa mudança de concepção e prática de ensino, segundo Chartier (2007), tornou, ao mesmo tempo, o papel da turma de alfabetização mais leve e mais pesado: mais leve no sentido da turma de alfabetização não ser mais "a" classe de alfabetização, e os conhecimentos dos alunos serem considerados desde a escola maternal (educação infantil); e mais pesada, porque - objetivo da turma de alfabetização não pode mais se reduzir ao ensino da codificação e decodificação, mas precisa "[...] articular o trabalho com o código e com a compreensão textual, tanto em sua recepção, como em sua produção" (CHARTIER, 2007, p. 151).

Nessa perspectiva, o documento faz referência às competências desenvolvidas na Grande Seção, último ano da educação infantil, relacionadas, entre outras coisas, à descoberta do princípio alfabético, e apresenta as competências que devem ser trabalhadas ao longo do ciclo nos quatro eixos do ensino da língua francesa: compreender e se exprimir na oralidade, ler, escrever e compreender o funcionamento da língua (FRANÇA, 2015).

Em relação à escrita, seu ensino deve contemplar tanto o domínio do gesto da escrita, como a produção de textos curtos, articulando esse ensino à aprendizagem da leitura. No que diz respeito à compreensão do funcionamento da língua, relacionado ao estudo da leitura e da escrita ao longo do ciclo 2, os conhecimentos envolvem questões ortográficas e de compreensão, privilegiando-se a formação das palavras (morfologia) e as relações entre elas (sintaxe). Especificamente nas turmas do Curso Preparatório (CP), primeiro ano do ensino fundamental, as atividades de ensino do francês devem enfatizar a reflexão acerca das palavras (significado e forma), considerando ainda as marcas de concordância, as variações de gênero e número, e os tempos verbais. 
É importante ressaltar que, diferentemente da França, as propostas curriculares publicadas a partir das décadas de 1980 e 1990 no Brasil, a exemplo dos Parâmetros Curriculares Nacionais (PCN) e das Diretrizes Curriculares Nacionais (DCN), não apresentam metas específicas para o ensino da língua portuguesa e nem tratam da especificidade da alfabetização. Tal especificidade era considerada apenas em programas como o Pró-Letramento - Programa de Formação Continuada de Professores dos Anos/Séries iniciais do Ensino Fundamental: alfabetização e linguagem (BRASIL, 2008) e o Pacto Nacional pela Alfabetização na ldade Certa - PNAIC (BRASIL, 2012), que acabaram servindo de referências para a elaboração de propostas curriculares na área de língua portuguesa, no que se refere aos anos iniciais do ensino fundamental.

No PNAIC, programa que vigorava antes da implementação da Base Nacional Comum Curricular (BNCC), o eixo de ensino referente aos conhecimentos linguísticos ressaltava capacidades relacionadas à compreensão dos princípios que regem o nosso sistema de escrita e que precisavam ser assegurados no primeiro ano, para que, no decorrer do ciclo Itrês primeiros anos do ensino fundamentall, outros conhecimentos relacionados à leitura e escrita pudessem ser trabalhados e consolidados (BRASIL, 2012).

Com a homologação da BNCC, em 20 de dezembro de 2017, o ciclo de alfabetização passou a envolver apenas os dois primeiros anos do ensino fundamental. De acordo com o referido documento, para que a criança se alfabetize, é preciso que consiga

[...] 'codificar e decodificar' os sons da língua (fonemas) em material gráfico (grafemas ou letras), o que envolve o desenvolvimento de uma consciência fonológica (dos fonemas do português do Brasil e de sua organização em segmentos sonoros maiores como sílabas e palavras) e o conhecimento do alfabeto do português do Brasil em seus vários formatos (letras imprensa e cursiva, maiúsculas e minúsculas), além do estabelecimento de relações grafofônicas entre esses dois sistemas de materialização da língua (BRASIL, 2017, p. 87-88, grifo nosso).

Percebemos, com isso, uma vinculação da alfabetização ao ensino explícito das correspondências entre fonemas e grafemas e ao método fônico, aspecto também presente na Política Nacional de Alfabetização, publicada no dia 11 de abril de 2019, por meio do Decreto n 9.765. A PNA considera 
a "consciência fonêmica" e a "instrução fônica sistemática" como dois dos componentes essenciais para a alfabetização, sendo o primeiro definido como - "[...] conhecimento consciente das menores unidades fonológicas da fala e a habilidade de manipulá-las intencionalmente [...]; e o segundo o [...] ensino explícito e organizado das relações entre os grafemas da linguagem escrita e os fonemas da linguagem falada" (BRASIL, 2019, p. 50).

Vivemos, portanto, um momento em que os documentos oficiais brasileiros para o campo da alfabetização parecem privilegiar um retorno ao método fônico de alfabetização. Contudo, salientamos que a materialização de um atendimento à heterogeneidade de conhecimentos dos aprendizes relaciona-se a aspectos que vão além de teorias, políticas e decretos, dentre eles, os saberes e práticas que os docentes mobilizam em suas ações cotidianas.

\section{A construção dos saberes na ação: o professor como agente ativo de sua prática alfabetizadora}

As práticas desenvolvidas pelos professores no espaço da sala de aula mobilizam diferentes saberes construídos ao longo do tempo e de sua carreira profissional. Tais saberes, que cotidianamente são movimentados na relação que o educador institui com seus pares, com as prescrições, com seus alunos, dentre outros atores, revelam a forma como os professores se constituem enquanto educadores por meio das ações docentes. Nessa direção, trata-se de uma ação que se refere ao conhecer, compreender e saber-fazer na função docente.

Nessa função, em meio aos múltiplos saberes instituídos, aqueles oriundos da experiência são os que mais se sobressaem. Segundo Tardif (2008), os saberes experienciais são adquiridos por meio das práticas cotidianas, e não se encontram, portanto, definidos nem nos currículos, nem nas instituições de formação, muito menos sistematizados como teoria e doutrina.

Segundo Goigoux (2007), no que se refere à prática docente, os saberes experienciais propiciam a construção de esquemas que dizem respeito às formas organizadas e estabilizadas de ensino que os professores acionam no processo de mediação entre as crianças e os conhecimentos, com vistas a operacionalizar um ensino ajustado às potencialidades de cada aluno. 
Diante disso, quanto mais experiente for o docente, mais esquemas de ação ele terá "armazenado". Tais esquemas, que nem sempre são mobilizados de forma planejada e intencional, precisam, conforme sinalizam Goigoux e Vergnaud (2005), ser analisados nas condutas dos professores em situações de sala de aula, pois dizem respeito aos registros de atividades que acontecem em interação com os alunos.

Com isso, os esquemas vão se estabilizando ao longo do tempo nas ações docentes, sendo necessária a existência de situações que podem ser repetitivas, porém singulares, para que eles sejam mobilizados. Atrelado a isso, a prática docente também pode agregar uma multi-agenda de gestos profissionais e também gestos didáticos que constituem os esquemas profissionais.

Os gestos profissionais correspondem, metaforicamente, segundo Bucheton e Soulé (2009), à ação do professor situada na diversidade de situações da sala de aula (o tempo; as interações; os saberes; as tarefas; a relação com o conhecimento; as atitudes dos alunos; entre outros aspectos) e à atualização de suas preocupações, podendo se referir tanto à palavra quanto aos movimentos corporais. Nessa perspectiva, as ações invariantes da atividade docente desenvolvidas desde o maternal até o ensino superior constituem o substrato dos gestos profissionais.

No que diz respeito às preocupações que regem a prática docente, Bucheton e Soulé (2009, p. 32, tradução nossa) destacam as ações de "[... 1 1) gerenciar e organizar o progresso da lição, 2) manter um espaço de trabalho e de colaboração linguística e cognitiva, 3) explicitar o significado do que está acontecendo, 4) apoiar o trabalho em andamento, 5) tudo isso com foco na aprendizagem de qualquer natureza". Tais preocupações se mostram como pilares que dão suporte ao ato ordinário na sala de aula, assim como para os conhecimentos, as experiências e habilidades do profissional docente.

Dentro desse quadro dos gestos profissionais, têm-se ainda as posturas assumidas pelos docentes no desenvolvimento de suas atividades, que funcionam como "[...] um esquema pré-construído de ações intelectuais e linguísticas que o sujeito evoca em resposta a uma situação ou tarefa escolar dada" (BUCHETON, 2006, p. 32, tradução nossa).

Bucheton e Soulé (2009), considerando a diversidade de comportamentos e ajudas ofertadas pelos docentes a seus alunos, sinalizaram para a existência de seis posturas: 1. postura de controle, que visa um enquadramento 
da situação, conduzindo de maneira rígida o progresso das tarefas e procurando fazer com que todo o grupo avance em sincronia; 2 . de acompanhamento, em que há uma ajuda pontual, individual ou coletiva, desenvolvida de maneira lateral em função do progresso da tarefa e dos obstáculos a serem superados; 3 . de deixar fazer, na qual o educador atribui aos discentes toda a responsabilidade por seu trabalho, autorizando-os a experimentar os caminhos que escolhem; 4. de sobreapoio ou contra-apoio, que diz respeito à interferência do docente, que, diante da necessidade de avançar mais rapidamente com a turma pode acabar fazendo a tarefa no lugar do aluno; 5. de ensino, na qual o professor formula, estrutura os saberes, as normas, com vistas à demonstração para os alunos; e, por fim, 6. uma postura chamada de "mágica" na qual o docente capta a atenção das crianças, mesmo que de forma momentânea, por meio de jogos, gestos teatrais, narrativas marcantes, entre outras ações.

Além dos gestos profissionais, temos ainda os gestos didáticos realizados pelos professores em sala de aula, que dizem respeito às intervenções didáticas que os professores realizam no processo de ensino-aprendizagem, com vistas ao desenvolvimento das capacidades dos alunos.

Nessa direção, os gestos didáticos são os gestos do professor quando se considera o objeto de ensino, ao passo que os gestos profissionais são mais amplos e englobam o agir docente em sua totalidade, permitindo caracterizar suas funções e tarefas independentemente da matéria de ensino.

No que diz respeito ao grupo de gestos didáticos que regem a prática docente, pautamo-nos nos quatro gestos fundamentais considerados por Schneuwly (2009), sendo eles: o de implementação do dispositivo didático; o de criação da memória didática; o de regulação e o de institucionalização. $\bigcirc$ primeiro - de "implementação do dispositivo didático" - refere-se à maneira como o professor irá apresentar o objeto de ensino ao seu aluno, ou seja, às intervenções didáticas que irá realizar. $\bigcirc$ segundo - "de criação da memória didática" - corresponde às intervenções nas quais o docente retoma os conteúdos que já foram ensinados com vistas a fazer relações com o que está ensinando no momento, o que possibilita a construção e partilha de um conhecimento comum pela classe. Já o terceiro gesto fundamental, "o de regulação", está voltado às intervenções que buscam a superação das dificuldades de aprendizagem dos alunos. E o quarto, de "institucionalização", direciona-se ao 
processo da ação docente de fixar os conhecimentos de um objeto de ensino que já foram instituídos por especialistas (MESSIAS; DOLZ, 2015).

Diante disso, sinalizamos que é na ação desenvolvida em sala de aula que o professor se torna professor, por meio da prática que realiza, das situações didáticas e pedagógicas que experimenta/(re)traduz/(re)organiza, e pelos procedimentos que utiliza.

\section{Metodologia}

Apresentaremos, nessa seção, o campo investigativo do estudo, os perfis das professoras e das turmas pesquisadas e os procedimentos metodológicos utilizados para coleta dos dados. $\bigcirc$ campo de nossa investigação se constituiu no espaço de duas escolas públicas inseridas em dois contextos diferentes: Brasil e França. No Brasil, a pesquisa foi realizada em uma escola da Secretaria de Educação da cidade do Recife - Pernambuco, localizada na periferia da Zona Norte do referido município. Na França, a escola campo da pesquisa se situava na cidade de Lyon, ao norte da região central do município, e recebia uma grande quantidade de alunos imigrantes que residiam próximo à escola.

As duas professoras participantes da pesquisa eram muito experientes. A professora brasileira (doravante PB), possuía 30 anos de experiência na docência, sendo 20 dedicados aos anos iniciais do ensino fundamental, e a professora francesa (doravante PF) tinha 20 anos de experiência como docente, sendo 5, dedicados aos anos iniciais. A professora do Brasil possuía graduação em Pedagogia, concluída no ano de 1994, e especialização em "Ensino de Educação Infantil e Ensino Fundamental 1", finalizada em 2000, ambos realizados na Universidade Federal de Pernambuco. Na época da pesquisa, atuava na turma do $1^{\circ}$ ano do ensino fundamental e, no contraturno de suas aulas (tarde e noite), exercia a atividade de vice-gestora em uma escola da rede estadual de ensino de Pernambuco. A turma da referida professora era composta por 24 alunos com média de idade de seis anos.

A professora da França era formada pelo Instituto Universitário de Formação de Professores (IUFM) e possuía um Diploma de Estudos Universitários Gerais (DEUG) pela Universidade de Lyon, em Matemática Aplicada e Ciências Sociais (MASS), obtido no ano de 1994. Ela ensinava em uma turma do Curso 
Preparatório (CP ) e não exercia outra atividade profissional. A turma de PF era composta por 25 alunos, com média de idade de 6 anos.

Em relação à trajetória metodológica, utilizamos a abordagem qualitativa, a partir da qual desenvolvemos observações de aulas, entrevistas com as professoras, análise documental referente às atividades contidas nos cadernos de classe dos alunos franceses e atividades diagnósticas de escrita de palavras com os alunos brasileiros. Na escola do Brasil, as observações de aula aconteceram em três semanas ao longo de um ano letivo (nos meses de abril, maio e outubro), totalizando quinze dias de observação. No caso da escola da França, as observações aconteceram durante cinco dias, na metade do ano letivo (meses de janeiro e abril). No primeiro mês, observamos três dias de aula, um dia a cada semana, e no segundo mês dois dias seguidos. Para cada dia de aula observado, realizamos registros em diário de campo, gravações de áudio das aulas e fotografias dos espaços e das atividades.

Avaliamos, em ambas as turmas, o perfil de entrada e saída dos alunos em relação à apropriação do sistema de escrita alfabética, utilizando-nos de uma atividade de escrita de palavras com apoio de figuras, realizada com os alunos brasileiros ao início e ao final do ano letivo, e das atividades de escrita contidas no caderno de classe dos alunos franceses.

Os dados obtidos tanto nas observações quanto nas entrevistas foram submetidos à análise de conteúdo categorial de Bardin (2004). Para a discussão dos dados obtidos, buscamos aporte em pesquisadores(as) diversos(as), entre os quais Ferreiro e Teberosky (1 999), Ferreiro (2001) e Morais (2012), assim como nas categorias elaboradas por Cruz (2012), sendo definidos os seguintes níveis para a apropriação do sistema de escrita alfabética:

- Pré-Silábico inicial (PI): nesse estágio, as escritas não têm relação com as partes sonoras das palavras.

- Pré-Silábico com início de fonetização (PII): as crianças começam a estabelecer algumas correspondências grafema/fonema nas sílabas ou letras iniciais e/ ou finais das palavras em suas escritas.

- Silábico (S): a criança registra uma letra para cada sílaba da palavra. Esse registro pode acontecer com base numa correspondência sonora da letra com a sílaba representada (silábico qualitativo), ou utilizando letras sem relação com a sílaba oral (silábico quantitativo). 
- Silábico-Alfabético (SA): as crianças começam a refletir no nível do fonema e a grafar mais de uma letra para representar uma sílaba.

- Alfabético inicial (Al): as crianças têm pouco domínio das correspondências letra/som, embora já tenham compreendido a base alfabética do nosso sistema de escrita (uma letra para cada fonema).

- Alfabético intermediário (All): apresentam um razoável domínio das correspondências letra/som, utilizando, predominantemente, grafemas com valor sonoro convencional.

- Alfabético consolidado (Alll): as crianças apresentam pouca dificuldade nas correspondências letra/som. Contudo, ainda cometem alguns erros ortográficos.

- Alfabético com escrita convencional (AIV): as crianças escrevem sem cometer nenhum erro ortográfico, podendo não utilizar corretamente a acentuação.

Essa caracterização dos níveis de escrita também tem relação com o estudo de Campelo (2015) que analisou e caracterizou a evolução psicogenética da escrita de crianças da escola pública do Rio Grande do Norte, tomando como referência as pesquisas de Emília Ferreiro e colaboradores. Nesse estudo, a autora caracterizou os níveis de escrita dos alfabetizandos norte-rio-grandenses por meio dos três períodos evolutivos propostos por Ferreiro (1990): $1^{\circ}$ período - distinção entre a representação icônica e não-icônica; $2^{\circ}$ período - construção de modos de diferenciação intrafigurais e interfigurais; $3^{\circ}$ período - fonetização da escrita.

Na seção a seguir, apresentaremos os resultados da pesquisa organizados em duas seções, uma para cada professora participante do estudo.

\section{A heterogeneidade de conhecimentos sobre a escrita alfabética dos alunos e a prática da professora do Brasil (PB)}

$\bigcirc$ tratamento da heterogeneidade de conhecimentos dos aprendizes sobre a escrita na sala de aula será analisado a partir das ações que PB desenvolvia ante esse fenômeno. Para isso, sinalizamos os níveis de apropriação do sistema de escrita alfabética (doravante SEA) que todos os alunos da sua turma apresentavam ao início do ano letivo. 
Como é de se esperar para uma turma do $1^{\circ}$ ano no início do ano letivo no Brasil, observamos uma grande quantidade de alunos que ainda se encontrava em níveis iniciais de escrita. Mais da metade dos aprendizes (60,8\%) apresentava uma hipótese pré-silábica, inexistindo, na maioria das diagnoses dessas crianças (39, $1 \%$ estavam no nível pré-silábico), algum tipo de correspondência fonológica entre a escrita e a pauta sonora das palavras apresentadas. Era baixo o número de alunos que estavam no nível silábico de escrita $(21,7 \%)$ e menor ainda os que evidenciavam uma hipótese silábico-alfabética $(17,3 \%)$. Ao início do ano, nenhum aluno apresentava uma hipótese alfabética de escrita.

Percebemos, então, que a classe era composta basicamente por dois grandes grupos de alunos: os que estavam no nível pré-silábico e aqueles que estavam no nível siábico. Dentro desses dois grandes grupos, podemos subdividir, no caso do primeiro nível, os que já começavam a realizar algum tipo de correspondência entre a escrita e a pauta sonora dos que ainda não estabeleciam nenhum tipo de correspondência e, no caso do segundo nível, os que escreviam uma letra para cada sílaba e dos que já atentavam de algum modo para o nível dos fonemas. Com isso, sinalizamos a existência de uma classe 12 heterogênea, mas que apresentava alunos com níveis de escrita próximos.

Apesar da vasta experiência de PB na docência, identificamos que ela tinha dificuldades em lidar com os diferentes conhecimentos dos alunos, assim como percebemos uma ausência de sistematicidade no trabalho de apropriação do sistema de escrita alfabética. No entanto, havia tentativas de atender à heterogeneidade da classe, relevados por meio da mobilização de "esquemas profissionais" (GOIGOUX, 2007), "gestos didáticos" (SCHNEUWLY, 2009; MESSIAS; DOLZ, 2015) e posturas (BUCHETON; SOULÉ, 2009).

As ações desenvolvidas por PB evidenciaram quatro tipos de esquemas profissionais que constituíam sua prática e estavam relacionados ao trato com a heterogeneidade, sendo estes: a interação professora-classe com reflexão coletiva; os agrupamentos; a ajuda/intervenção e as atividades diferenciadas.

As interações que a professora desenvolvia com a classe com vistas à reflexão coletiva eram o esquema mais utilizado, mobilizado em nove das quinze aulas observadas (9/15), seguido dos agrupamentos (5/15). Isso demonstra que a docente buscava contemplar a heterogeneidade do saber fazer sobre a escrita alfabética nas situações de ensino realizadas 
simultaneamente com todo o grupo. Os esquemas correspondentes às ajudas/ intervenções (2/15) e às atividades diferenciadas (1/15) também se fizeram presentes, mas não foram muito mobilizados em sua prática, revelando-se de modo mais tímido. Além disso, articulado a alguns desses esquemas, a docente também mobilizava o gesto didático da regulação e posturas de controle, apoio, sobreapoio ou contra-apoio, que serão logo mais descritas.

A professora do Brasil ensaiava ações que buscavam atender à heterogeneidade da turma, apesar do ensino necessitar de ajustes em relação às demandas dos aprendizes em algumas situações. Em outras palavras, PB testava maneiras de contemplar os diferentes saberes sobre a escrita da sua turma. Nessa direção, o trabalho coletivo se mostrava como mola propulsora para o atendimento desse fenômeno em sala, havendo, nesse sentido, a mobilização do esquema profissional relacionado à "interação professora-classe para a reflexão coletiva", utilizado nos momentos de escrita de palavras.

Ao mobilizar esse esquema, é importante destacar que a docente utilizava o gesto didático da regulação, criando meios para os alunos encontrarem a resposta e superarem os obstáculos (SCHNEUWLY, 2009; MESSIAS; DOLZ, 2015), ao mesmo tempo em que também assumia posturas de "controle, sobreapoio ou contra-apoio" (BUCHETON; SOULÉ, 2009), desconsiderando, na maioria das situações, o erro do aluno, antecipando algumas respostas e fazendo a atividade no lugar das crianças. Esse tipo de postura era evidenciado quando a docente realizava a reflexão sobre a escrita de palavras, mas desconsiderava as letras ditas pelos alunos, ou quando antecipava suas respostas, deixando de refletir sobre os próprios erros dos aprendizes.

Em uma das aulas observadas (Aula 01 1), ao trabalhar com o alfabeto móvel, as crianças estavam organizadas em duplas com níveis de conhecimentos distintos e, além de solicitar a montagem de algumas palavras, PB optou por refletir sobre a quantidade de letras e sílabas, em detrimento da sua escrita. Para isso, as palavras foram inicialmente escritas no quadro (ESCOLA, MENINA, MENINO), realizou-se a contagem de suas letras e sílabas para posteriormente serem montadas pelas crianças com o alfabeto móvel.

Essa estratégia de escrever a palavra no quadro antes mesmo de solicitar a escrita da criança pode ser analisada como uma "postura de sobreapoio ou contra-apoio" (BUCHETON; SOULÉ, 2009) para as crianças avançarem mais rápido na atividade. Além disso, também pode ser interpretada como 
uma tentativa de controlar os erros das crianças, tendo em vista que seria uma boa oportunidade de problematizar as hipóteses de escritas apresentadas pela turma.

Em relação aos agrupamentos, apesar da organização das carteiras da sala ser em dupla, com crianças que apresentavam níveis de conhecimentos próximos e outras hipóteses distintas, a solicitação de um trabalho conjunto e cooperativo não era constante, sendo os agrupamentos estimulados em cinco das quinze aulas observadas. Para isso, a professora fomentava a formação desses grupos, mas deixava a cargo das próprias crianças a escolha de onde ficar, revelando certa inconsistência nesse trabalho, uma vez que o mais adequado seria a docente, enquanto conhecedora das dificuldades dos aprendizes, direcionar os tipos de agrupamento.

Todavia, como os níveis de conhecimento sobre a escrita da turma eram heterogêneos, isso acabava refletindo na maioria dos agrupamentos, mesmo com as escolhas sendo feitas pelos próprios alunos. Nesses agrupamentos, percebemos a perspectiva de PB em instituir o trabalho cooperativo de ajuda entre os aprendizes. Além disso, essas situações também serviam para diminuir as interações mais próximas da professora com os alunos que apre14 sentavam dificuldades, uma vez que ela deixava os aprendizes trabalharem de modo mais autônomo, tendo o colega como suporte para alguma dúvida que viesse a surgir.

A mobilização do esquema relacionado às atividades diferenciadas aconteceu junto a esse trabalho com os agrupamentos, quando a professora propôs um trabalho com jogos de alfabetização envolvendo a associação da imagem à palavra, e da imagem à primeira letra da figura. Esse esquema foi mobilizado em uma única aula (Aula 14), do conjunto de aulas observadas, coadunando com o que expõe Morais (2012), que a realização de atividades diferentes é, ainda, uma dificuldade para as docentes no tratamento com a heterogeneidade da classe.

Por fim, a ajuda e intervenção junto a um aprendiz que apresentava dificuldades de aprendizagem com a escrita era uma conduta realizada de modo não planejado e intencional, mas que buscava dar conta da dificuldade de aprendizagem de um aluno especificamente. Tal esquema foi mobilizado para solução de episódios semelhantes, que aconteceram em dois dias do conjunto de aulas observadas, e que se referiam à dificuldade do aluno para 
realizar uma atividade que envolvia a reflexão sobre o sistema de escrita alfabética.

Essas ações pontuais e os demais esquemas, gestos e posturas mobilizados revelam a tentativa de PB em "[...] possibilitar, no grau mais elevado possível, a participação de todos os alunos nas diferentes atividades e tarefas, mesmo se o seu nível de competência, seu interesse ou seus conhecimentos forem em um primeiro momento muito escassos e pouco adequados" (ONRUBIA, 1996, p. 134). Tal tentativa, dentre as ações outrora explicitadas, mostra-se como tateamentos feitos pela professora para o atendimento à heterogeneidade, sendo a ação coletiva a maneira mais "fácil" para PB realizar um trabalho em que todos pudessem ser contemplados.

Diante disso, os tateamentos evidenciados por meio de esquemas, ações e posturas pouco consistentes, acabaram refletindo nas aprendizagens acerca do sistema de escrita alfabética. Ao final do ano letivo, identificamos avanços de boa parte dos aprendizes, mas também a permanência de alguns na mesma hipótese com que haviam iniciado o ano letivo. Além disso, chamamos a atenção para a incidência de crianças que ainda apresentavam níveis pré-silábicos ao final do ano $(34,7 \%)$, chegando a ultrapassar a quantidade de alunos com hipótese alfabética (26\%). Os de nível silábico e silábico-alfabético totalizavam cerca de 39\%. Enfim, poucas crianças chegaram ao final do ano escrevendo com base em uma correspondência entre os sons menores que as sílabas (fonemas) e os grafemas. Na seção a seguir, apresentamos as análises do contexto francês.

\section{A heterogeneidade de conhecimentos sobre a escrita alfabética dos alunos e a prática da professora da França $(\mathrm{PF})$}

A análise das atividades de escrita contida nos cadernos dos aprendizes desde o início do ano letivo possibilitou traçar o perfil de entrada das crianças do Curso Preparatório da escola francesa acerca dos conhecimentos sobre o sistema de escrita alfabética. Tal caderno era utilizado apenas no contexto escolar e continha as atividades de classe realizadas individualmente pelos alunos, assim como a correção da docente realizada posteriormente à finalização da tarefa pela criança. 
Identificamos, com base na análise das escritas contidas nos cadernos das crianças, que a maioria dos aprendizes iniciaram o CP com uma hipótese alfabética de escrita (88\%), tendo apenas um aluno (4\%) uma hipótese pré-silábica inicial e dois alunos (8\%) hipótese silábico-alfabética. Tal panorama é bem diferente do apresentado no $1^{\circ}$ ano do ensino fundamental no Brasil, no qual a maioria das crianças evidenciava níveis iniciais de escrita ao início do ano letivo. Na turma do CP, percebemos que a heterogeneidade recaía sobre o domínio das correspondências letra/som, uma vez que grande parcela da classe já compreendia que as letras representam ou notam a pauta sonora das palavras que falamos.

Diante disso, as práticas da professora precisavam atender as crianças que ainda não pensavam de forma alfabética, com vistas a fazê-las alcançar tal hipótese, ao mesmo tempo em que contemplava os alunos desse nível, com vistas a consolidar as correspondências grafema/fonema, assim como as normas e regras ortográficas. Para lidar com esses diferentes conhecimentos, PF, assim como PB, também mobilizava "esquemas profissionais" (GOIGOUX, 2007), "gestos profissionais e didáticos" (MESSIAS; DOLZ, 2015; SCHNEUWLY, 2009), assim como as posturas (BUCHETON; SOULÉ, 2009) em suas ações.

16 Identificamos o uso de seis esquemas na prática da professora francesa: os agrupamentos; as ajudas e intervenções; as atividades diferenciadas; o atendimento individualizado; a interação professora-aluno nas situações coletivas de ensino e a interação professora-classe com vistas à reflexão coletiva. Apesar de alguns destes serem os mesmos mobilizados por PB, veremos que a maneira como PF os mobilizou em sua prática foi diferente.

É importante ressaltar que esses esquemas, que também agregavam gestos, apresentavam-se de maneira articulada na prática da docente e em muitas situações de modo concomitante, tendo em vista que os agrupamentos eram propostos para a realização de tarefas diferentes, ao passo que alguns alunos se beneficiavam das ajudas, intervenções e atendimentos feitos pela professora.

Os agrupamentos eram um esquema frequente, sendo realizado em quatro das cinco aulas observadas (4/5). Isso porque a prática da professora era pautada no trabalho com ateliês, onde a classe era organizada em quatro grupos para a realização das atividades diárias. Nessa organização, cada grupo era formado por crianças com diferentes conhecimentos sobre a leitura e 
a escrita, tendo em vista a intenção da professora em possibilitar a ajuda mútua entre os aprendizes. Nesse sentido, eram agrupamentos intencionais que vislumbravam um papel ativo dos alunos.

Antes de propor as atividades para os grupos, a professora sempre explicava cada uma das tarefas, deixando os aprendizes cientes do que deveria ser feito e iniciando a preparação dos alunos para a cooperação. Isso contribuía também para o gerenciamento da atmosfera da classe, uma vez que esse gesto profissional, mediante as interações dos grupos, possibilitava, dentre outras situações, o confronto entre os aprendizes para resolver questões em comum, conforme sinaliza Bucheton e Soulé (2009).

Os trabalhos em grupos envolviam atividades tanto de consolidação da escrita alfabética quanto de aspectos da gramática, e duravam cerca de uma hora, durante quatro dias da semana. Para isso, a sala era organizada em quatro grupos, sendo três grupos de seis e um de sete aprendizes que alternavam os quatro tipos de tarefas que eram propostas, uma para cada grupo, ao longo da semana. Geralmente, duas ou três dessas tarefas eram mais mecânicas, envolvendo pintura, desenho ou matemática (adição) para que as crianças as respondessem autonomamente, ao passo que as demais eram acompanhadas pela professora e envolviam exercícios que versavam sobre a apropriação e consolidação do SEA.

Esses momentos serviam tanto para PF dar atenção mais específica a um dos grupos dos ateliês quanto para poder intervir junto a alguns aprendizes nos diferentes grupos ou fora deles. Essas ajudas e intervenções eram mobilizadas corriqueiramente (3/5) e de forma consciente e planejada, assim como evidenciavam gestos profissionais de apoio (BUCHETON; SOULÉ, 2009), haja vista a intenção da docente em favorecer a compreensão, a aprendizagem e o crescimento desses aprendizes com dificuldades que recebiam suas ajudas e intervenções.

A ajuda fornecida a determinados alunos no mesmo instante em que os aprendizes trabalhavam em grupos evidenciava uma diferenciação dentro de uma situação que já era diferenciada. Isso se revelou também quando PF aproveitava esses momentos dos trabalhos nos ateliês para realizar um atendimento individualizado, em duas das cinco aulas observadas (2/5), junto aos aprendizes que apresentavam dificuldades com a leitura e a escrita ou que 
precisavam avançar em outras competências. Para isso, também havia as atividades diferenciadas.

$\bigcirc$ uso dessas atividades, em três das cinco aulas observadas (3/5), revelava o olhar atento à heterogeneidade de conhecimentos sobre a escrita alfabética que permeava a classe, mostrando-se como um esquema que era mobilizado pela consciência da professora daquilo que os alunos já sabiam e o que ainda precisavam aprender. Para isso, PF, a partir de uma das aulas (Aula 05), passou a adotar uma nova organização: pastas nas cores preta, vermelha e verde contendo diferentes atividades em cada uma delas; e um cartaz com os nomes dos alunos separados pelas cores da pasta, fixado na parede abaixo do quadro.

Essa separação, assim como as atividades, foi proposta com base nos diferentes níveis de conhecimentos acerca da escrita apresentados pelas crianças. Nessa direção, todos os alunos classificados na cor preta apresentavam hipóteses alfabéticas consolidadas; os da cor vermelha mesclavam crianças de nível alfabético consolidado com intermediário e os da cor verde reuniam as crianças de nível alfabético intermediário que apresentavam um pouco mais de dificuldades. Com isso, as atividades de cada uma das pastas buscavam contemplar e atender às especificidades de cada um desses grupos.

Tais atividades, desenvolvidas para complementar a atividade pedagógica, eram feitas durante a aula, mas sem o acompanhamento direto da docente, uma vez que nesses momentos se assumia a "postura de deixar fazer" (BUCHETON; SOULÉ, 2009), mas um deixar fazer que se assentava dentro das possibilidades de resolução das crianças.

É importante destacar que as interações estabelecidas por PF com determinadas crianças ou com todo o grupo nos momentos coletivos também se revelavam como um esquema profissional, mobilizado em três das cinco aulas observadas (3/5). Tais interações, imbuídas do gesto didático da regulação (MESSIAS; DOLZ, 2015; SCHNEUWLY, 2009) e do gesto profissional de apoio (BUCHETON; SOULÉ, 2009) buscavam propiciar aos aprendizes a superação de suas dificuldades, levando-os a compreender, dizer e fazer o que estava sendo proposto.

gesto de apoio (BUCHETON; SOULÉ, 2009), de levar o aluno a aprender, também se fazia presente nos momentos em que PF mobilizava o esquema de reflexão coletiva na qual a interação acontecia entre a professora 
e toda a classe. Isso aconteceu em três das cinco aulas observadas (3/5). Nessas situações coletivas, toda a turma era estimulada a refletir sobre a escrita adequada das palavras e seus fonemas. $O$ procedimento adotado pela professora era o de, nas interações com a turma, construir um caminho que levasse os alunos ao entendimento do que estava sendo solicitado. Essa prática, assim como os esquemas, gestos e posturas mobilizados, acabaram reverberando nas aprendizagens dos alunos ao final do ano letivo.

Todas as crianças terminaram o ano escolar no nível alfabético com $68 \%$ com hipóteses alfabéticas consolidadas e os outros 32\% no nível alfabético intermediário. Por outro lado, percebemos a permanência de alguns alunos nos mesmos níveis de apropriação do sistema de escrita em que começaram o ano, em especial no alfabético consolidado. No entanto, a permanência no nível alfabético consolidado não se caracteriza como algo grave, haja vista que a consolidação desses aspectos se fará ao longo dos dois outros anos do Ciclo de Aprendizagens Fundamentais e que a ortografia e acentuação de palavras no idioma francês é algo complexo. Sendo assim, todas as crianças concluíram a classe do CP compreendendo o funcionamento do SEA, diferentemente do que observamos no contexto brasileiro na turma do $1^{\circ}$ ano em que muitos alunos terminaram o ano sem atingir a hipótese alfabética ou sem consolidar as correspondências som/grafia.

\section{Considerações finais}

Neste artigo, buscamos analisar as práticas de professoras do $1^{\circ}$ ano do ensino fundamental no Brasil e na França no atendimento à heterogeneidade de conhecimentos sobre a escrita alfabética dos alunos, assim como os diferentes níveis de apropriação do sistema de escrita das crianças de ambas as turmas ao início e final do ano letivo.

Ao analisarmos os conhecimentos das crianças sobre o SEA com base nos estudos de Ferreiro e Teberosky (1999), Ferreiro (2001) e Morais (2012), chamamos a atenção para a disparidade, no início do ano letivo, entre os aprendizes do $1^{\circ}$ ano do ensino fundamental no Brasil e os alunos do CP na França. Enquanto a maioria das crianças francesas iniciou o primeiro ano do ciclo de aprendizagens com hipóteses silábicas e alfabéticas, compreendendo que a escrita representa a pauta sonora das palavras, no Brasil, os alunos da 
turma investigada apresentavam hipóteses iniciais de escrita, com predominância do nível pré-silábico.

Tal cenário nos leva a considerar a necessidade de políticas públicas de alfabetização no Brasil que comecem a pensar e vivenciar a compreensão do sistema de escrita alfabética antes mesmo dessa etapa, desde a educação infantil, como acontece na França, e como é proposto por Morais (2012) e Soares (2016).

No quesito referente ao trabalho com a heterogeneidade de conhecimentos sobre a escrita alfabética, identificamos "esquemas profissionais" (GOIGOUX, 2007) e "posturas, gestos didáticos e profissionais" (BUCHETON; SOULÉ, 2009; MESSIAS; DOLZ, 2015; SCHNEUWLY, 2009) mobilizados por ambas as docentes com vistas a atender a esse fenômeno.

A mobilização dos esquemas no bojo das ações pedagógicas foi operada de maneira diferente pelas professoras, apesar de alguns destes terem sido os mesmos (os agrupamentos, as ajudas/intervenções, as atividades diferenciadas, a reflexão coletiva). Isso porque ambas apresentavam posturas diferentes em relação ao conhecimento que possuíam sobre o que seus alunos 20 já sabiam e o que ainda precisavam aprender para que pudessem avançar em suas aprendizagens sobre a escrita.

Destacamos esse conhecimento e avaliação sobre os saberes dos aprendizes como um dos elementos-base para o uso dos referidos esquemas de modo mais intencional. Enquanto a professora francesa evidenciava esse conhecimento, a professora brasileira demonstrava dificuldades em avaliar e lidar com os diferentes conhecimentos dos alunos. Em outras palavras, PB tinha consciência da necessidade de atender aos diferentes saberes das crianças sobre a escrita, mas parecia não saber como agir.

A busca da professora brasileira em contemplar as individualidades e dificuldades de alguns alunos por meio de agrupamentos não produtivos e de ajudas e intervenções pontuais revelavam-se enquanto tateamentos (CHARTIER, 2000) que visavam gerir os diferentes conhecimentos de escrita existentes na sala de aula. No entanto, da forma como eram conduzidos, acabavam por não contribuir de maneira significativa para as aprendizagens dos estudantes. Com isso, eles progrediam na escolaridade sem apresentar avanços significativos em seus conhecimentos sobre a escrita. Tais dados vão ao encontro do que foi apontado por Souza e Costa-Maciel (2021) sobre o fato de um 
terço dos(das) estudantes da rede de ensino do Recife concluírem o ciclo de alfabetização ( $3^{\circ}$ ano do ensino fundamental) sem consolidar os objetivos de aprendizagem de leitura aferidos na avaliação de rede.

No caso do contexto francês, destacamos as progressões de conhecimentos acerca da escrita evidenciadas por boa parte dos aprendizes da turma do CP, em que os encaminhamentos e intervenções docentes se mostraram de forma mais efetiva tanto no trato da heterogeneidade quanto das atividades relacionadas aos eixos da leitura e da escrita. Com isso, identificamos a possibilidade de avanços por parte dos aprendizes que dispõem de uma prática que atente e, consequentemente, atenda às dificuldades e diferentes conhecimentos apresentados no grupo/classe.

Sendo assim, consideramos que não é a retomada de um método fônico, de perspectiva homogeneizadora, como propõe a atual Política Nacional de Alfabetização, que propiciará a aprendizagem da língua escrita, mas sim, a valorização da heterogeneidade de saberes sobre a leitura e a escrita que permeiam os alunos da classe. É preciso que as professoras e professores saibam avaliar os conhecimentos dos alunos e, com base neles, organizem suas intervenções pedagógicas para trabalhar na perspectiva da heterogeneidade no sentido de fazer todos os alunos avançarem.

\section{Notas}

1 Programa de formação continuada de professores alfabetizadores proposto pelo Ministério da Educação em 2012, com a integração entre profissionais das redes públicas de diversas Secretarias de Educação municipais e estaduais, e professores e alunos de diferentes universidades do Brasil. Tal programa propôs um conjunto de "direitos de aprendizagens" relacionados às diferentes áreas de ensino.

2 A turma do CP corresponde, no Brasil, ao $1^{\circ}$ ano do ensino fundamental.

3 A diferença em relação ao quantitativo e periodicidade de observações do contexto francês com o brasileiro se deu pela dificuldade inicial em encontrarmos escolas aptas a nos receber, haja vista a tramitação exigida pelo sistema francês de ensino, como também pela duração do doutorado sanduíche que impossibilitou as observações ao final do ano.

4 A opção por analisarmos os cadernos de classe dos alunos se explica pelo fato de não termos tido a oportunidade de ingressar na escola ao início do ano letivo e não estarmos presente ao final do ano escolar. 


\section{Referências}

BARDIN, Laurence. Análise de conteúdo. Lisboa: Edições 70, 2004.

BRASIL. Ministério da Educação. Pró-letramento: Programa de formação continuada dos anos/séries iniciais do Ensino Fundamental: Alfabetização e Linguagem. Brasília: Ministério da Educação/Secretaria de Educação Básica, 2008.

BRASIL. Ministério da Educação. Pacto Nacional pela Alfabetização na Idade Certa: currículo na alfabetização: concepções e princípios: ano 1. Brasília: Ministério da Educação/ Secretaria de Educação Básica, 2012.

BRASIL. Ministério da Educação. Base Nacional Comum Curricular. Brasília: Conselho Nacional de Secretários de Educação/União Nacional dos Dirigentes Municipais de Educação, 2017.

BRASIL. Decreto $\mathbf{n}^{\circ}$ 9.765, de 11 de abril de 2019. Institui a Política Nacional de Alfabetização. Disponível em: hitps://legislacao.presidencia.gov.br/. Acesso em: 2 jun. 2019.

BUCHETON, Dominique. Les postures d'écriture et de lecture: la diversité des modes de penser-parler-apprendre. Langage et Pratiques, Lausanne, n. 37, p. 29-39, jun. 2006.

22 BUCHETON, Dominique; SOULÉ, Yves. Les gestes professionnels et le jeu des postures de l'enseignant dans la classe: un multi-agenda de préoccupations enchâssées. Éducation et didactique, Varia, v. 3, n. 3, p. 29-48, out. 2009.

CAMPELO, Maria Estela Costa Holanda. Psicogênese da língua escrita: referência fundamental para a compreensão do processo de alfabetização. Revista Educação em Questão, Natal, v. 53, n. 39, p. 186-217, set./dez. 2015.

CHARTIER, Anne Marie. Fazeres ordinários da classe: uma aposta para a pesquisa e para a formação. Educação e Pesquisa, São Paulo, v. 26, n. 2, p. 157-168, jul. 2000.

CHARTIER, Anne Marie. A leitura e sua aquisição: modelos de ensino, modelos de aprendizagem. In: CHARTIER, Anne Marie. Práticas de leitura e escrita: história e atualidade. Tradução Ruth Silviano Brandão. Belo Horizonte: Ceale/Autêntica, 2007.

CRUZ, Magna do Carmo Silva. Tecendo a alfabetização no chão da escola seriada e ciclada: a fabricação das práticas de alfabetização e a aprendizagem da escrita e da leitura pelas crianças. 2012. 350f. Tese (Doutorado em Educação) - Programa de PósGraduação em Educação, Universidade Federal de Pernambuco, Recife, 2012.

FERREIRO, Emília; TEBEROSKY, Ana. Psicogênese da língua escrita. Porto Alegre: Artmed, 1999. 
FERREIRO, Emília. A escrita... antes das letras. In: SINCLAIR, Hermine. (org.). A produção de notações na criança: linguagem, números, ritmos e melodias. Tradução Maria Lúcia F. Moro. São Paulo: Cortez/Autores Associados, 1990.

FERREIRO, Emília. Reflexões sobre alfabetização. São Paulo: Cortez, 2001.

FRANCCA. Programme d'enseignement du cycle des apprentissages fondamentaux (cycle 2). Paris: Ministère de l'Éducation nationale, 2015.

GOIGOUX, Roland. Rien de plus pratique qu'une bonne théorie? Si, deux ! Les concepts de schème et de genre au service d'une analyse didactique de l'activité d'enseignement. In: MARYVONNE, Merri. Activité humaine et conceptualisation: questions à gérard vergnaud. Toulouse: PUM, 2007.

GOIGOUX, Roland; VERGNAUD, Gérard. Schèmes professionnels. Revue de l'association internationale de recherches en didactique du français, AiRDF, n. 36, p. 7-10, 2005.

MESSIAS, Carla; DOLZ, Joaquim. As noções de gestos e de agir didático para a formação de professores de línguas: interfaces do trabalho docente. Cadernos Cenpec, São Paulo, v. 5, n. 1, p. 44-67, 2015.

MORAIS, Artur Gomes de. Sistema de escrita alfabética. São Paulo: Editora Melhoramentos, 2012.

ONRUBIA, Javier. Ensinar. Criar zonas de desenvolvimento proximal e nelas intervir. In: COLL, César; MARTíN, Elena; MAURI, Teresa; MIRAS, Mariana; ONRUBIA, Javier; SOlÉ, Isabel; ZABALA, Antoni. O construtivismo na sala de aula. São Paulo: Editora Ática, 1996.

SCHNEUWLY, Bernard. L'objet enseigné. In: SCHNEUWLY, Bernard; DOLZ, Joaquim. (org.). Des objets enseignés en classe de français: le travail de l'enseignant sur la rédaction de textes argumentatifs et sur la subordonnée relative. Genève: Presses Universitaires de Rennes, 2009.

SOARES, Magda. Alfabetização: a questão dos métodos. São Paulo: Contexto, 2016.

SOUZA, Alexsandra Felix de Lima; COSTA-MACIEL, Débora Amorim Gomes. Ensinar a ler: finalidades docentes no contexto da alfabetização. Revista Educação em Questão, Natal, v. 59, n. 59, p. 1-23, jan./mar. 2021.

TARDIF, Maurice. Saberes docentes e formação profissional. Petrópolis: Vozes, 2008. 
Dra. Nayanne Nayara Torres da Silva Universidade de Pernambuco (Brasil) Grupo de Estudos e Pesquisa em História e Educação no Sertão do São Francisco (GEPHESF) Orcid id: https:/ / orcid.org/0000-000 1-7778-0699

E-mail: nayanne.torres@upe.br

Dra. Eliana Borges Correia de Albuquerque Universidade Federal de Pernambuco (Brasil) Programa de Pós-Graduação em Educação Grupo de Estudo em Alfabetização, Prática Docente e Formação de Professor (GEALPRAFOR) Orcid id: https://orcid.org/0000-0002-71 62-8466 E-mail: eliana.balbuquerque@gmail.com

Recebido 2 maio 2021 Aceito 27 jul. 2021 